\title{
The impact of E-dictionary strategy training on EFL class
}

\author{
Toshiko Koyama ${ }^{1}$
}

Received: 28 March 2015/Accepted: 15 June 2015/Published online: 7 July 2015

(C) Springer Berlin Heidelberg 2015

\begin{abstract}
The present study attempts to clarify how effective strategy training has been with pocket electronic dictionaries for non-English major EFL learners in an English reading class. The study was designed on the basis of the results of my previous study (LET Kansai Chapter Collected Papers 15:109-119, 2015), which concluded that the reading task with dictionary strategy training for 10 weeks might positively affect the participants' attitude to leaning, and also the dictionary strategies and reference skills have been well retained. The present study, therefore, provided the participants with: (1) metacognitive tasks as an outside-class activity; (2) setting a collaborative learning environment with peer review; (3) an explicit presentation of the strategies and reference skills with a projector. The results showed that the strategies and reference skills could have been retained by the nonEnglish majors doing these tasks. Additionally, their attitude to learning English seemed to be improved in the present study.
\end{abstract}

Keywords Pocket electronic dictionary - Reference skills · Dictionary strategies · Dictionary training

\section{Introduction}

Japan is known as a unique country whose learners' dictionaries have well developed from the dawning of the Meiji Era (1868-1912; Tono 2006). Since then, there have appeared a wide range of different types of dictionaries such as those on

This article is a revised version of the paper presented at the JACET 53rd (2014) International Convention at Hiroshima City University, Japan.

Toshiko Koyama

mtkoyama@osaka-ohtani.ac.jp

1 Osaka Ohtani University, Tondabayashi, Japan 
paper, CD-ROM, and the Web. In particular, the pocket electronic dictionary (hereafter E-dictionary) appeared around the turn of the $21 \mathrm{st}$ century. The E-dictionary, which is recognized as a handheld computer with integrated reference materials (e.g., Yamada 2014), has rapidly replaced the paper dictionary in East Asian countries. Market research indicates a considerable demand for E-dictionaries in universities, colleges, and even in high schools (Nakamura 2003). According to the data of the Japan Business Machine and Information System Industries Association, in fact, demand for E-dictionaries in Japan has been growing until recently.

As Kaya (2013) mentioned, presently, although the popularity of the smart phone has been growing exponentially for "Digital Natives" (Prensky 2001), this mobile communication tool has not been applied widely to educational programs so far. Consequently, the E-dictionary has not declined in popularity among Japanese high school and college students up to now.

\section{Previous studies}

A series of studies have reported the differences between E-dictionaries and paper dictionaries in learners' look-ups and the effect on learning with the learners' feedback (e.g., Koyama and Takeuchi 2003, 2004, 2005, 2007). The comparative studies have focused on a key difference in the interface between the two dictionary types: the paper dictionary allows the user to look at opposing two pages at a glance, including the looked-up entry; the E-dictionary provides learners with only small chunks of information regarding the L2 equivalents, owing to the small screen display. This is in stark contrast with the paper dictionary that can offer sufficient information around target words. The results show that although the E-dictionary can enhance learners' look-up frequency and can reduce the time for FL reading, it does not necessarily guarantee the same degree of retention of the looked-up words nor comprehension of the text as the paper version does.

Osaki and Nakayama (2004) compared the E-dictionary and the paper one for the differences in comprehension of unknown words, reading comprehension of the texts, and retention of the looked-up words. They concluded that the use of E-dictionary might help learners to find appropriate meanings and thus temporarily facilitate better text comprehension when reading texts containing numerous unfamiliar words within a specified time limit. Shizuka (2003) conducted a similar kind of comparative study, and claimed the superiority of E-dictionaries over paper dictionaries based on the results of a speed test with 77 university EFL students.

Taking these findings into consideration, Koyama and Takeuchi (2009) attempted to find effective strategies for dictionary use by qualitatively examining look-up behaviors of good language learners. This study was aimed at leading the advantages of E-dictionary use toward better L2 learning. On the basis of the findings in Koyama and Takeuchi (2009), Koyama (2010) conducted a pilot study on the training of the effective use of E-dictionary. The study was conducted with 14 undergraduate students in the English reading class for 8 weeks. As a task for outside-class activity, a vocabulary check sheet was distributed to the students in advance. They were instructed to look up words and phrases unfamiliar to them in 
each article in their textbook and jot down the most appropriate L2 equivalents of them beforehand. Some dictionary strategies found in Koyama and Takeuchi (2009) as well as reference skills (e.g., Nation 2001) were taught by the instructor while reading the textbook in class. They were given pre- and post-tests consisting of a reading text and comprehension quizzes, and a 16-item questionnaire to assess which E-dictionary reference skills and strategies were actually used before and after the experiment. The results show that the participants looked up fewer words and used fewer dictionary strategies or reference skills than they did in the pre-test. However, their comprehension of the text significantly improved in the post-test. One of the implications of the study was that dictionary strategy training should be given to learners more explicitly in accordance with the points outlined by Nyikos and Fan (2007) which claim that metacognitive instruction has a significant positive effect on L2 learning.

The second study (Koyama and Yabukoshi, 2011) was conducted with eight college students under similar conditions to Koyama (2010). The study was carried out for the particular purpose of verifying whether dictionary strategies and reference skills were retained when learners were explicitly taught them. The results show that dictionary strategies, when taught explicitly with metacognitive tasks, can be retained.

Improved studies, Koyama (2013) and Koyama (2015) build on the findings of Koyama and Yabukoshi (2011). The participants whose major was English in both studies were explicitly taught E-dictionary reference skills and strategies by the instructor at the beginning of the training session given as a part of the reading class. In addition, a collaborative learning environment was set up during the training, that is to say, almost all the participants explained each essay in the textbook in detail, referring to their dictionaries, in front of the class. The other participants could ask questions freely during the presentations, and the instructor made some comments on the presentations when necessary. From the results of tests and 17-item questionnaires given before and after the trainings, those skills and strategies appeared to be retained.

\section{The study}

\subsection{Purpose}

The present study examined whether or not the training in reference skills and strategies conducted in the previous studies (Koyama 2013, 2015; Koyama and Yabukoshi, 2011) was an effective means of improving reading comprehension especially for non-English major Japanese students of English. In addition, the study assessed how well they could retain E-dictionary reference skills and strategies. Accordingly, the study was to replicate Koyama (2015) with non-English major Japanese EFL students under the same conditions, and conducted in an L 2 reading class.

\subsection{Participants}

The participants in the study were 14 undergraduate students whose major was social sciences. Given both the results of in-class quizzes and a 45 -item pre-class 
cloze test $(M=18.1, S D=3.90)$, their English proficiency level ranged from intermediate to false-beginners. Based on the answers to the questionnaire given to them in advance, no one had experienced training in E-dictionary reference skills and strategies.

\subsection{Text and dictionary used}

The reading material used in the study was a textbook consisting of 15 essays for Japanese college students. Each essay was composed of approximately 600 words, including several words deemed to be unfamiliar to the participants. The textbook was written by a native speaker of English and topics range from industries, life, culture, and education to gender equality.

During the training, the participants used their own E-dictionaries which they are using for their daily English study. A survey conducted by the author revealed that they have been using their dictionaries for years; at least since they were high school students. Although their E-dictionaries incorporate several dictionaries and has some useful functions, the participants preferred to use a bilingual dictionary. In fact, Schmitt (1997) reported that Japanese learners have a tendency toward using a bilingual dictionary. They were instructed, therefore, to use Taishukan's Genius English-Japanese Dictionary (3rd or 4th edition) for the training, which is one of the most popular English-Japanese dictionaries.

\subsection{Procedure}

The procedure of the experiment is summarized in Table 1. On the first day of the training, the participants were provided with an orientation to the course.

In each of the classes, a vocabulary check sheet was distributed to the participants for an outside-class task. It was entirely left to their discretion whether they would fill out the sheets. Most participants, however, looked-up words and phrases unfamiliar to them in each essay and jotted down the most appropriate L1 and/or L2 equivalents or example sentences of the looked-up words on the sheets beforehand. They were motivated to do so since every time they finished reading an essay in the textbook, a

Table 1 Procedure of the experiment

\begin{tabular}{ll}
\hline Week & Details of the training \\
\hline 1 & Orientation of the course, pre-test, questionnaire (cloze test) \\
$2-9$ & $<\mathbf{1 s t}$ session $>$ \\
& Explanations of reference skills for E-dictionary and four effective dictionary strategies \\
& Reading comprehension while using E-dictionary (guided by the instructor) \\
& $<\mathbf{2 n d}$ session> \\
$10-19$ & $\begin{array}{l}\text { Reading comprehension while using E-dictionary } \\
\text { (without the help of the instructor) } \\
20\end{array}$
\end{tabular}


review exercise including reading comprehension and vocabulary quizzes was administered. While taking the quizzes, the participants were not allowed to consult their dictionaries but to refer to their vocabulary check sheets.

As is shown in Table 1, the training period was divided into two sessions. At the beginning of the first session, the participants were explicitly taught four E-dictionary strategies, as well as some other reference skills, by the instructor such as: (1) guessing meanings from the context before actual look-ups; (2) associating dictionary information with their background knowledge; (3) checking usage examples of the target words; and (4) paying attention to pronunciation of the target words and pronouncing them. These strategies were identified in Koyama and Takeuchi (2009), which were considered to be effective for SLA (e.g., Baddeley, 1990; Hulstijn et al. 1996; Laufer and Hulstijn 2001; Nation 2001). In the second session, one of the participants explained each essay in front of the class, asking other participants some questions while freely referring to their E-dictionary, which means they played the role of instructor. During both sessions, the projector was set up in front of the classroom, so that the instructor and the participants could share the display of the E-dictionary.

Before and after the training sessions, the participants were given pre- and posttests made up of 15 sentences containing words with multiple meanings and idiomatic phrases. They were required to read and answer them while using their dictionaries. To verify which reference skills and dictionary strategies they actually used during the tests, a 17-item questionnaire was also administered (see Appendix). Additionally, the questionnaire included a space where the participants freely write their opinions on their look-up behaviors and the training they received.

\section{Results}

The results of the present study were analyzed in the same manner as described in Koyama (2013, 2015). Table 2 displays a comparison of the mean values between pre- and post-tests. One point was given to each sentence when the subjects could jot down the most appropriate L1 equivalent to the context in the test, and thus the full mark was 15 for "Quiz scores". "Number of lookups" indicates that the number of the words and the phrases the participants had actually consulted in each test. The results of statistical analysis are indicated in the table. Since the number of the participants was small, a non-parametric, the Wilcoxon signed-rank test was applied (Siegel and Castellan 1988).

Table 2 Results of quiz scores and number of lookups

\begin{tabular}{lcc}
\hline & Pre-test & Post-test \\
\hline Quiz scores & 9.2 & $11.7^{*}$ \\
Number of lookups & $21.9^{* *}$ & 16.4 \\
\hline
\end{tabular}

$* p<0.05$

** $p<0.01$ 
As shown in the table, there is significant difference in "Quiz Scores" between the pre- and the post-tests at $p<0.05$, which indicates an improvement in accuracy. In respect of the number of lookups, the value reveals a significant difference, which means that the participants consulted the dictionaries fewer times to translate each sentence into Japanese in the post-test. The results indicate that the 18-week training for reference skills and strategies might positively affect the participants reading comprehension.

A 17-item questionnaire was administered to assess their retention of E-dictionary reference skills and strategies they were instructed in the first session of the training. The participants checked off each skill and strategy in the questionnaire if they actually applied them during both tests. One point was given to each checked item. Some representative comments made by the participants in the questionnaire are presented in Fig. 1.

The values in Table 3 reveal that the number of checked item slightly increased; however, no significant difference was found at the .05 level. It appears that some of the four targeted strategies, which were explicitly taught to the participants in the training, had been known beforehand and was used by the students. Nevertheless, from the participants feedback in Fig. 1, it is obvious that the participants learned to consciously consult their dictionary after the training.

From the favorable comments in Fig. 2, the use of the projector is deemed to be effective for the dictionary training.

Comments on taking on the role of an instructor during the second session of the training were made (see Fig. 3). Since no negative comments on the activity were made, they seemed to view their opportunities positively as a whole.

\section{Discussion and conclusion}

The summary of the findings follow. First, the 18-week training for reference skills and strategies could positively affect the participants' reading comprehension. The quiz scores and the number of lookups in Table 2 indicate that their reading comprehension has sufficiently improved. It should be noted, however, that the number of lookups in the present study had significantly decreased after the dictionary training. This stands in sharp contrast to Koyama (2015), whose number of the lookups had increased after the ten-week training. Second, although we could

\footnotetext{
1. I got quite accustomed to considering which L2 equivalents are suitable for the context in case of a word with multiple meanings.

2. I am making it a rule to confirm whether the target word has idioms or not.

3. Recently, I became conscious of the part of speech of the target word.

4. I deliberately guess meanings or pronunciations of the target word before actually looking up.

5. I make it a rule to register looked-up words into the memory of my own E-dictionary, and try to memorize them in my free time.
}

Fig. 1 Student comments from the open-ended questions (1) 
Table 3 Results of 17-item questionnaire

\begin{tabular}{lll}
\hline & Pre-test & Post-test \\
\hline Number of the items (17) & 6.3 & 7.0 \\
Number of the targeted strategies (4) & 2.4 & 2.5 \\
\hline
\end{tabular}

All values are n.s

1. E-dictionary display onto the screen helped me to understand which part I should have a look at in my E-dictionary or which explanation my classmates were reading in their E-dictionaries.

2. I enjoyed and profited from looking at the E-dictionary display onto the screen together with my classmates.

3. I was able to confirm what I looked up in my dictionary when the instructor or classmates put their E-dictionary display onto the screen.

Fig. 2 Student comments from the open-ended questions (2)

1. I was happy to think and learn with my classmates together.

2. Their serious attitudes towards learning was an incentive that made me study more.

3. I was nervous about explaining what I studied at home in front of the class, but playing a role in teaching was a valuable experience for me.

Fig. 3 Student comments from the open-ended questions (3)

not find any significant differences between before and after the training, E-dictionary reference skills and strategies seemed to be retained by the participants. Student feedback in Fig. 1 provides concrete proof that they leaned to consciously consult the dictionary.

The main results agreed with those obtained in Koyama (2015); nevertheless, there are some differences in the results between the two studies. A point to which special attention should be paid is the students different majors: English in Koyama (2015) and social studies in the present study. To be more precise, the participants in the present study were not necessarily motivated to learn English compared with the previous study. Additionally, the duration of the dictionary training in the present study was much longer, and was divided into two sessions. These differences might have an influence upon the results.

Despite the differences in the results of the two studies described above, the findings in the present study prove that the dictionary training in reference skills and strategies can be an incentive to form a desirable EFL leaning environment. During the training, the participants tackled the assigned tasks in a positive manner, and voluntarily made a class presentation with detailed commentary on each essay. They were considered to spontaneously consult an E-dictionary in the process. At the same time, these metacognitive tasks supported the retention of a complicated cognitive process which dictionary consultation requires. This is in strict accordance 
with the findings in Fraser (1999) and Nyikos and Fan (2007). These tasks also might help to internalize reference skills and strategies they learned. What is more, the collaborative learning environment, as well as assigned tasks, seemed to support the retention of a complex cognitive process which dictionary consultation entails (e.g., Tono 2001). These tasks and activities appear to be necessary to explain the effect.

Based on the findings described above, we can maintain that the students were helped by training in dictionary use. The consideration, therefore, would lead us to believe that effective use of E-dictionary provides L2 learners with scaffolding (van Lier 1996). We hope the present study will shed light on a new aspect of dictionary use in EFL education. Note, however, the accumulation of data on a lot of condition examples is needed hereafter. Further experiments should be made in the future.

Acknowledgments This research is partially supported by the Grant-in-Aid for Scientific Research (C), No. 23520724, awarded to the author of this article in the fiscal year of 2011-2013. The author would like to express her deep gratitude to Professor Masamichi Mochizuki of Reitaku University and Professor Thomas Robb of Kyoto Sangyo University for their valuable comments on an earlier version of this article. The author also wishes to thank the reviewers for their insightful comments on this paper.

\section{Appendix}

17 questions asked in the questionnaire

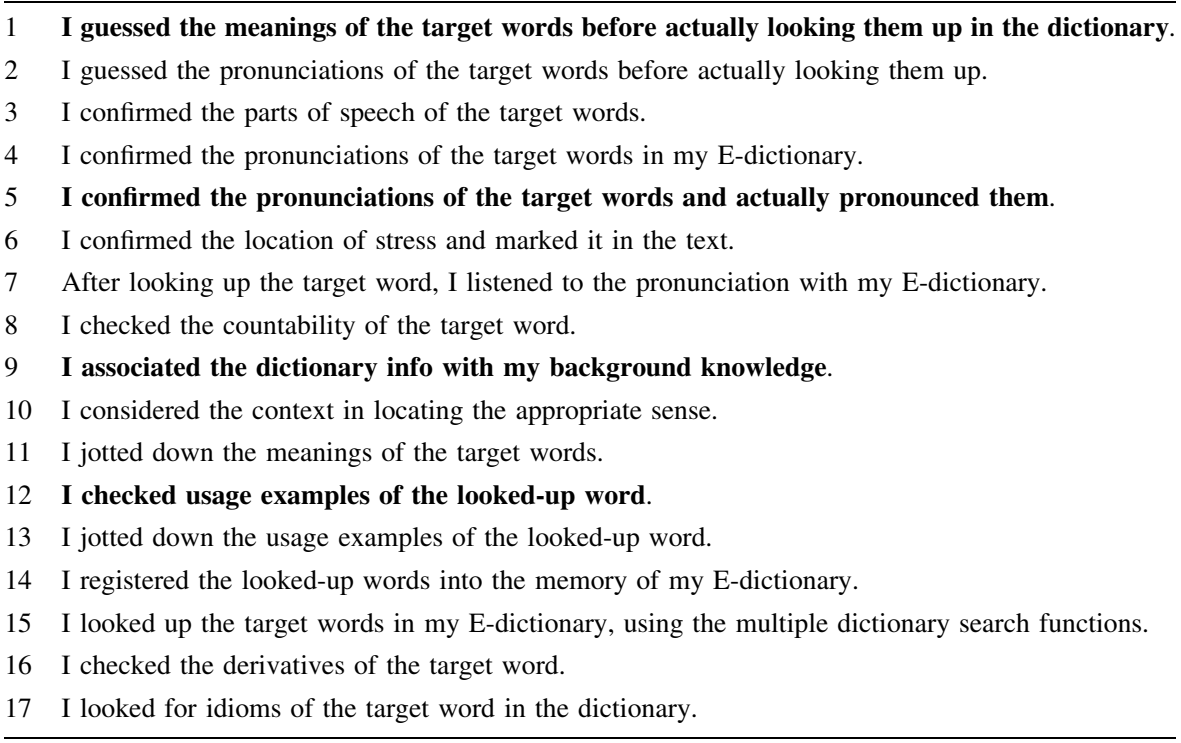

The questions were originally given in Japanese

Bold fonts indicate the targeted dictionary strategies 


\section{References}

Baddeley, A. 1990. Human memory: Theory and practice. Hove: Lawrence Erlbaum Associates LTD.

Fraser, C.A. 1999. Lexical processing strategy use and vocabulary learning through reading. Studies in Second Language Acquisition 21: 225-241.

Hulstijn, J.H., M. Hollander, and T. Greidanus. 1996. Incidental vocabulary learning by advanced foreign language students: the influence of marginal glosses, dictionary use, and reoccurrence of unknown words. The Modern Language Journal 80: 327-339.

Japan Business Machine and Information system industries Association: The statistical data. http://www. jbmia.or.jp/statistical_data/index.php. Accessed 18th May 2015.

Kaya, T. 2013. Gengogakusyu niokeru Mobairu Tanmatsu no Atarashii Katsuyouhou (New methods of mobile assisted language learning) Gakushuin Jyoshi Daigaku Kiyo (Bulletin of Gakushuin Women's College) Vol. 15. 19-29.

Koyama, T. 2010. Teaching strategies for an effective use of E-dictionary: a pilot study. Osaka Ohtani Daigaku Eigoeibunngaku Kenkyu (Osaka Ohtani University Studies in English Language and Literature) 37: 35-43.

Koyama, T. 2013. Enhancing learners' E-dictionary skills through strategy training. In Lexicography and Dictionaries in the Information Age: Selected papers from the 8th ASIALEX International Conference, eds. D. A. Kwary, N. Wulan, and L. Musyhda, 173-178.

Koyama, T. 2015. Denshijisho no Horyakushidou no Kouka (How does E-dictionary strategy training contribute to EFL learning?). LET Kansai Chapter Collected Papers 15: 109-119.

Koyama, T., and O. Takeuchi. 2003. Printed dictionaries vs. electronic dictionaries: a pilot study on how Japanese EFL learners differ in using dictionaries. Language Education and Technology 40: 61-79.

Koyama, T., and O. Takeuchi. 2004. Comparing electronic and printed dictionaries: how the difference affected EFL learning. JACET Bulletin 38: 33-46.

Koyama, T., and O. Takeuchi. 2005. Does an assigned task result in better retention of words? Two empirical studies on hand-held electronic dictionaries. Language Education and Technology 42: 119-132.

Koyama, T., and O. Takeuchi. 2007. Does look-up frequency lead to better comprehension of EFL learners? Two empirical studies on electronic dictionaries. Calico Journal 25: 110-125.

Koyama, T., and O. Takeuchi. 2009. How effectively do good language learners use handheld electronic dictionaries: a qualitative approach. Language Education and Technology 46: 131-150.

Koyama, T., and T. Yabukoshi. 2011. Denshijisho Shiyo no Horyakushidou eno Ichikousatsu: metaninchi Katsudou wo Toriirete (A study on teaching strategies for an effective use of E-dictionary: Implementing metacognitive tasks). LET Kansai Chapter Collected Papers 13: 79-92.

Laufer, B., and J.H. Hulstijn. 2001. Incidental vocabulary acquisition in a second language: the construct of task-induced involvement. Applied Linguistics 22(1): 1-26.

Nakamura, M. 2003. The use of the electronic IC dictionary in the EFL environment. In Proceedings of the 3rd ASIALEX Biennial International Conference (Meikai University, Chiba, Japan), eds. M. Murata, S. Yamada, and Y. Tono, 346-350.

Nation, I.S.P. 2001. Learning vocabulary in another language. Cambridge: Cambridge University Press.

Nyikos, M., and M. Fan. 2007. A review of vocabulary learning strategies: Focus on language proficiency and learner voice. In Language Learner Strategies: Thirty years of research and practice, ed. A.D. Cohen, and E. Macaro, 251-273. Oxford: Oxford University Press.

Osaki, S., and N. Nakayama. 2004. Denshijisyo vs. insatujisyo-Yuyosei to jikkousei no chigainituiteno kosatu (Electronic dictionary vs. paper dictionary: a comparison of the two dictionary studies). Bulletin of Tokyo Denki University, Arts and Sciences, No. 2: 77-83.

Prensky, M. 2001. Digital natives, digital immigrants. On the Horizon 9(5), 1-6. MCB University Press.

Schmitt, N. 1997. Vocabulary learning strategies. In Vocabulary: Description, Acquisition and Pedagogy, 199-227, eds. N. Schmitt, and M. McCarthy. Cambridge: Cambridge University Press.

Shizuka, T. 2003. Efficiency of information retrieval from the electronic and the printed versions of a bilingual dictionary. Language Education and Technology 40: 15-33.

Siegel, S., and N.J. Castellan Jr. 1988. Nonparametric statistics for the behavioral sciences, 2 nd ed. Singapore: McGraw-Hill Inc.

Tono, Y. 2001. Research on dictionary use in the context of foreign language learning: Focus on reading comprehension. Tübingen: Niemeyer. 
Tono, Y. 2006. English bilingual lexicography in Japan: Meeting serious challenges. In English lexicography in Japan, eds. S. Ishikawa, K. Minamide, M. Murata, and Y. Tono, 18-25. Tokyo: Taishukan.

van Lier, L. 1996. Interaction in the language curriculum: Awareness, autonomy, and authenticity. London: Longman.

Yamada, S. (2014). Dictionary use in urban society: Web-based and hand-held electronic dictionaries. In Proceedings of the "Language Phenomena in Urban Society" Conference, ed. D. A. Kwary, 1-7. Surabaya: Airlangga University Press. 